\title{
Islamic Science Camp: Program Pembelajaran IPA yang Menyenangkan dengan Konsep Islami dan Kecintaan pada Alam
}

Ro'i Khatul Jannah ${ }^{1}$, Muhamad Imaduddin ${ }^{2 *}$, Muhammad Fathurriza ${ }^{3}$, Muhammad Ali Sofyan $^{4}$, Helmi Auliya ${ }^{5}$, Atmim Nurona ${ }^{6}$, Izzatul Ulya ${ }^{7}$, Abu Choir ${ }^{8}$

1,2,3,4,5,6,7 Program studi Tadris Ilmu Pengetahuan Alam, Institut Agama Islam Negeri Kudus, Indonesia

${ }^{8}$ Program studi Pendidikan Agama Islam, Institut Agama Islam Negeri Kudus, Indonesia

*Correspondence Address: imad@iainkudus.ac.id

\begin{abstract}
This study aims to reveal how the concept of learning program design at the Islamic Science Camp (ISC), as well as to show the impressions of children and parents on the various ISC activities. This research consists of three stages, namely define, design and development. The trial subjects came from 11 elementary school (Islamic) institutions consisting of 28 students. The data were collected using (1) observation checklists; (2) documentation; (3) field notes sheets; and (4) impression sheets. Data analysis used tabulation techniques, narrative descriptions, and word cloud analysis. The science topics tested were related to (1) changes in the form of substances; (2) the concept of force and pressure; (3) matter and its classification; (4) the concept of energy; (5) aquatic ecosystems; and (6) plant morphology. Islamic values are emphasized in directing children's habituation activities, as well as providing children's motivation through Islamic figures in the fields of science and technology. Science projects include (1) a rotary ice cream making project; (2) launching a water rocket project; (3) making air freshener; (4) studying Islamic science; (5) building a ship and launching it; (6) river tracing and fishing; (7) making key chains from resin; and (8) making ecoprinting using pounding technique. Various positive impressions were obtained from the children and parents involved, and on the sustainability aspect, it was shown that there were repetitions and follow-up experiments by children outside the ISC program.
\end{abstract}

Keywords: islamic science camp, science learning, love of nature, islamic science concept.

\begin{abstract}
ABSTRAK
Kajian ini bertujuan untuk mengungkap bagaimana konsep desain program pembelajaran pada Islamic Science Camp (ISC), serta menunjukkan kesan anak dan orang tua pada ragam akivitas ISC. Riset ini terdiri dari tiga tahapan yaitu define, design, dan development. Subyek uji coba berasal dari 11 instansi SD/MI yang terdiri dari 28 siswa. Pengumpulan data menggunakan (1) daftar cek observasi, (2) dokumentasi, (3) lembar catatan lapangan, dan (4) lembar kesan. Analisis data menggunakan teknik tabulasi, deskripsi naratif, serta word cloud analyisis. Topik IPA yang diujicobakan berkaitan dengan (1) perubahan wujud zat; (2) konsep gaya dan tekanan; (3) materi dan klasifikasinya; (4) konsep energy; (5) ekosistem perairan; dan (6) morfologi tumbuhan. Nilainilai Islam ditekankan pada pengarahan kegiatan habituasi anak, serta pemberian motivasi anak melaui tokoh-tokoh Islam bidang sains dan teknologi. Proyek sains mencakup (1) proyek pembuatan es krim putar; (2) proyek meluncurkan roket air; (3) pembuatan pengharum ruangan; (4) kajian sains islami; (5) proyek pembuatan kapal dan meluncurkannya; (6) susur sungai dan tangkap ikan; (7) pembuatan gantungan kunci dari resin; dan (8) pembuatan ecoprinting dengan teknik pounding. Beragam kesan positif diperoleh dari anak dan orang tua yang terlibat, serta pada aspek keberlanjutan ditunjukkan adanya repetisi dan eksperimen lanjutan oleh anak di luar program ISC.
\end{abstract}

Kata kunci: Islamic Science Camp, pembelajaran IPA, cinta alam, konsep islami sains. 


\section{PENDAHULUAN}

Ilmu Pengetahuan Alam (IPA) atau sains menjadi bagian kurikulum pendidikan anak yang begitu penting untuk dikembangkan di berbagai negara (Asoko, 2000). Kondisi ini menjadi semakin krusial karena ilmu pengetahuan dan teknologi semakin berkembang dengan pesat. Meskipun pada akhirnya IPA yang diajarkan kepada anak belum tentu membekali arah karirnya di masa depan, IPA tetap erat kaitannya dengan kehidupan sehari-harinya serta dapat membekali anak sebagai warga negara yang melek IPTEK di masa depan.

Urgensitas tersebut ternyata berbeda dengan apa yang tengah dialami oleh Indonesia. Kondisi yang perlu diperhatikan berkaitan dengan literasi anak beradasarkan skor PISA (Programme for International Student Assessment). Hasil PISA menunjukkan kemampuan anak usia 15 tahun di bidang matematika, sains, dan membaca. Skor literasi membaca Indonesia berada pada peringkat 72 dari 77 negara, skor literasi matematika ada di peringkat 72 dari 78 negara, dan skor literasi sains ada di peringkat 70 dari 78 negara (The OECD Programme for International Student Assessment, 2019). Melihat kondisi yang demikian, perlu dilakukan beragam upaya untuk memperbaiki kondisi pembelajaran IPA di Indonesia.

Banyak kajian telah berupaya memperbaiki kondisi pembelajaran IPA. Perbaikan kualitas pembelajaran IPA mengarah pada meneguhkan kembali hakikatnya sebagai sebuah proses, produk, dan sikap ilmiah (Anita, 2013; Chiappetta \& Koballa, 2010; Wisudawati \& Sulistyowati, 2014). Banyak pendidik yang masih menekankan pembelajarannya hanya pada produk yang artinya lebih pada fakta, data, konsep, prinsip, dan teori-teori ke-IPA-an. Kondisi perkembangan zaman menjadikan produk IPA begitu melimpah, sehingga pengajarannya tidak harus disampaikan sepenuhnya. Pembelajaran akan menjadi lebih lengkap dan bermakna jika siswa mampu mengkonstruksi pengetahuannya sendiri melalu proses yang ada (Imaduddin, 2017; Zion \& Mendelovici, 2012). "IPA sebagai proses" dalam hal ini mengarah pada aktivitas penelitian ataupun proyek. Adapun IPA sebagai sikap ilmiah, menyangkut perilakunya dalam berproses pada kegiatan ilmiah, penelitian ataupun proyek IPA. Selain pada ketiga aspek ini, IPA tidak boleh lagi diajarkan hanya sebagai satu disiplin ilmu tetapi juga harus disinggungkan dengan bidang keilmuan lain (National Science Teachers Association, 2003). Dalam kurikulum pendidikan nasional Indonesia pun, Kompetensi Inti (KI) dirancang dalam empat kelompok yang saling terkait yaitu sikap beragama (KI 1), sikap sosial (KI 2), pengetahuan (KI 3), dan penerapan pengetahuan (KI 4). Keempat kelompok tersebut menjadi acuan Kompetensi Dasar (KD) dan harus dikembangkan dalam setiap kegiatan pembelajaran secara terintegrasi. Kompetensi yang berkaitan dengan sikap keagamaan dan sosial dikembangkan secara tidak langsung ketika peserta didik mempelajari pengetahuan (KI 3) dan penerapan pengetahuan (KI 4) (Badan Penelitian dan Pengembangan, 2013).

Sisi lain, sebagai salah satu bagian dari penghuni bumu, manusia seharusnya mampu mengamati, memahami, memprediksi, mencegah, dan menyesuaikan diri terhadap berbagai perubahan kondisi fisik bumi secara biologis dan geologis maupun kondisi sosial dan ekonomi. Hal ini mengarah pada tantangan perlunya proses belajar yang terus menerus, mengintegrasikan, menggunakan pengetahuan secara komprehensif untuk kesejahteraan masyarakat. Dengan demikian, diperlukan restrukturasi tujuan, konten, dan pendekatan pendidikan. Pendekatan dalam pendidikan sains berdampak langsung pada kontribusi sains yang diajarkan pada pembangunan berkelanjutan (Imaduddin, 2017; Zidny \& Eilks, 2018). Konsep ini menekankan bagaimana kita diajarkan dalam menghargai lingkungan untuk mempertahankan kondisi bumi ini agar dapat terus dinikmati oleh lintas generasi. Konsep-konsep kecintaan lingkungan dan IPA sudah diajarkan secara tersirat maupun tersurat dalam Al-Qur'an maupun sunnah yang digunakan sebagai pedoman hidup muslim (Golshani, 1998, 2004; Imaduddin, 2020; Thamrin, 2017; Wardani \& Mulyani, 2013). Dengan demikian, IPA sangat penting untuk diajarkan kepada anak agar mereka dapat menjadi individu yang memahami dan menghayati pentingnya keberadaan alam dan lingkungan tempat tinggalnya, serta nilai-nilai yang diajarkan oleh Agama Islam. 
Program untuk menumbuhkan kecintaan anak kepada alam dengan nuansa Islam perlu dikembangkan agar pembelajaran IPA lebih bermakna. Pembelajarn IPA anak juga perlu diwujudkan dalam model pembelajaran yang menyenangkan. Pembelajaran IPA yang dirancang perlu menekankan pada aktivitas hands-on (Cakiroglu, 2007; Cassim, 2013; Inan \& Inan, 2015) untuk menumbuhkan kecintaan terhadap alam (Barlia, 2008; Karpudewan, Ismail, \& Mohamed, 2013) serta menerapkan nilai-nilai Islam (Amril, 2018; Imaduddin, 2019; Imaduddin \& Khafidin, 2018; Imaduddin \& Zuhaida, 2019). Salah satu upaya pengembangan pembelajaran IPA yang perlu dilakukan adalah melalui aktivitas outdoor leaning yang tidak dibatasi oleh ruang kelas ataupun laboratorium (Rahmawati et al., 2020). Beragam kajian telah memverifikasi kondisi bahwa pembelajaran luar ruangan memiliki dampak pada peningkatan minat, keinginan, motivasi, serta aspek-aspkel lainnya dalam proses pembelajaran sains (Dillon et al., 2016; Hofstein \& Rosenfeld, 1996; Rickinson et al., 2004). Outdoor learning juga merupakan salah satu bentuk kontekstualisasi pembelajaran yang dapat menumbuhkan peningkatan kualitas desain pembelajaran, mendorong dialog dan interaksi, serta meningkatkan pemahaman tentang makna pembelajaran sepanjang hayat (Ash \& Wells, 2006; Bamberger \& Tal, 2008; Martin, 2006). Oleh karena itu, riset ini mencoba mendesain konsep desain program pembelajaran yang dinamakan sebagai Islamic Science Camp dan mengimplementasikannya.

Uji coba desain kegiatan outdoor learning diselenggarakan melalui aktivitas camp (perkemahan) yang didalamnya termuat kegiatan habituasi yang menekankan nilai-nilai ke-Islaman, serta aktivitas pembelajaran IPA yang berorientasi pada proyek hands-on activity yang menumbuhkan kecintaan pada alam. Kesemuanya coba diramu dan diimplementasikan pada siswa level sekolah dasar yang heterogen dari aspek kelas formal, maupun area. Hal yang menarik adalah riset ini bertujuan untuk mengungkap bagaimana konsep desain program pembelajaran pada Islamic Science Camp, serta menunjukkan kesan anak dan orang tua pada ragam akivitas program yang akan digunakan untuk perbaikan desain di masa mendatang.

\section{METODOLOGI}

Studi ini mengungkap rangkaian kegiatan riset dan pengembangan program pendidikan yang menggunakan penyederhanaan model 4D dari Thiagarajan, Semmel, \& Semmel (1974). Adapun riset ini masih berupa siklus pertama dari beberapa tahapan yang akan dikerjakan di masa mendatang. Riset awal ini terdiri dari tiga tahapan utama yaitu tahap define, design, dan development. Rincian tahapan riset dan pengumpulan data ditunjukkan pada Tabel 1.

Tabel 1. Rincian Tahapan Riset dan Pengembangan Program ISC

\begin{tabular}{|c|c|c|c|}
\hline No & Tahapan Riset & Deskripsi Tahapan & Teknik Pengumpulan Data \\
\hline 1 & Define & $\begin{array}{l}\text { Kegiatan ini berujuan agar aktivitas camp, serta } \\
\text { analisis materi IPA dan nilai-nilai Islam sesuai } \\
\text { dengan bentang alam dan potensi yang ada pada } \\
\text { lokasi. }\end{array}$ & $\begin{array}{l}\text { Daftar cek observasi } \\
\text { Dokumentasi }\end{array}$ \\
\hline 2 & Design & $\begin{array}{l}\text { Kegiatan merumuskan dan mendesain rangkaian } \\
\text { kegiatan yang akan disajikan dalam tahapan } \\
\text { selanjutnya }\end{array}$ & $\begin{array}{l}\text { Lembar catatan lapangan } \\
\text { Dokumentasi }\end{array}$ \\
\hline 3 & Development & $\begin{array}{l}\text { Tahapan kelayakan desain, serta uji coba } \\
\text { implementasi desain. }\end{array}$ & $\begin{array}{l}\text { Lembar catatan lapangan } \\
\text { Lembar kesan (subyek uji coba) } \\
\text { Daftar cek observasi } \\
\text { Dokumentasi }\end{array}$ \\
\hline
\end{tabular}

Jenis data yang diambil pada riset ini menekankan pada data kualitatif. Data yang diperoleh diharapkan dapat menunjukkan lebih mendalam kondisi yang ada serta menunjukkan secara spesifik rangkaian pembelajaran yang dilaksanakan pada ISC. Kegiatan uji coba dilaksanakan di area Madrasah Alfa Kids yang berlokasi di Kecamatan Cluwak, Kabupaten Pati, 
Jawa Tengah. Pengambilan subyek uji coba dilakukan secara random sesuai dengan kesediaan siswa dan orang tua/wali. Subyek uji coba berasal dari 11 instansi SD/MI di area karesidenan Pati, Jawa Tengah. Kesemuanya 28 siswa yang terdiri dari 14 siswa laki-laki dan 14 siswa perempuan yang merupakan siswa kelas $2(\mathrm{~N}=1)$, kelas $4(\mathrm{~N}=10)$, kelas $5(\mathrm{~N}=11)$, dan kelas 6 $(\mathrm{N}=6)$. Kesemuanya diambil dari siswa yang bersedia mengikuti program ini. Analisis data menggunakan teknik tabulasi, deskripsi naratif, serta word cloud analyisis menggunakan software QDA Miner Lite (Adu, 2019).

\section{TEMUAN DAN PEMBAHASAN}

\section{Tahap Define}

Tahap ini bertujuan untuk menentuan kondisi kelayakan lokasi pelaksanaan program dan kesesuaian lokasi untuk menerapkan konsep dan metode pembelajaran IPA luar kelas. Oleh karena itu, dilaksanakan kegaiatn analisis situasi bentang alam dan analisis proyek dan materi pembelajaran, serta nilai-nilai Islami.

\section{Analisis Situasi Bentang Alam}

Tahapan ini dilakukan dengan menganalisis beberapa titik lokasi. Beberapa pertimbangan penting merujuk pada lokasi aktivitas Mandi, Cuci, Kakus (MCK) anak, lokasi tidur anak, lokasi beribadah, serta aktivitas proyek pembelajaran IPA. Gambaran bentang alam dan titik lokasi kegiatan ISC ditunjukkan pada Gambar 1. Kondisi representatif untuk pelaksanaan habituasi anak, serta pembelajaran berbasis proyek IPA menjadi hal penting keterlaksanaan program ISC. Bentang alam luar ruangan yang dapat dimanfaatkan optimal untuk kegiatan ISC adalah sawah dan sungai kecil yang dimanfaatkan oleh penduduk untuk irigasi area persawahan. Kondisi area dalam ruangan juga representatif untuk pembelajaran anak secara kooperatif dan pelaksanaan habituasi yang mendasarkan pada nilai-nilai Islam.

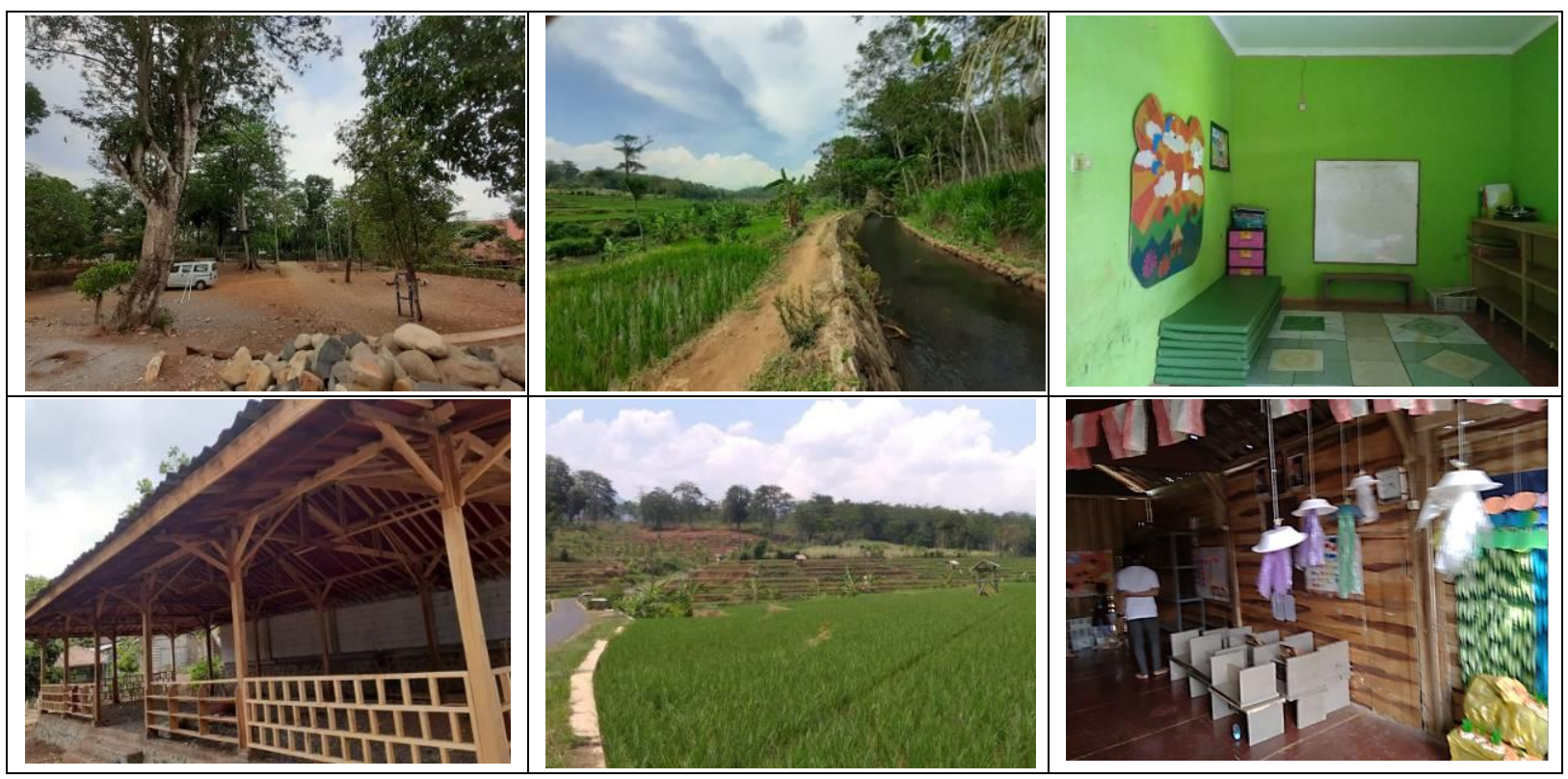

Gambar 1. Kondisi Bentang Alam untuk Implementasi Desain Program Islamic Science Camp

\section{Analisis Proyek dan Materi Pembelajaran dan Nilai-nilai Islam}

Proyek topik materi pembelajaran IPA diset dengan sistem FGD (Focus Group Discussion) antara peneliti dengan pakar di bidang Pendidikan IPA dan bidang psikologi. Hasil FGD memperoleh hasil topik IPA yang akan diujicobakan berkaitan dengan (1) Perubahan wujud zat; 
(2) Konsep Gaya dan Tekanan; (3) Materi dan Klasifikasinya; (4) Konsep Energi; (5) Ekosistem perairan; dan (6) Morfologi Tumbuhan. Adapun nilai-nilai Islam akan ditekankan pada pengarahan kegiatan habituasi anak, serta pemberian motivasi anak dengan mengenalkannya pada tokoh-tokoh Islam yang menggeluti bidang sains dan teknologi.

\section{Tahap Design}

Pada tahap ini dirancang rangkaian kegiatan utama pada ISC dengan memperhatikan tiga komponen utama yaitu pembelajaran IPA, kecintaan pada alam, dan nilai-nilai Islam. Rancangan kegiatan ini telah mengalami perubahan beberapa kali dengan beragam pertimbangan yaitu: (1) Durasi waktu, durasi program diset agar dapat selesai secara singkat tetapi tetap bisa memberikan kesan mendalam. Pertimbangan setting durasi waktu memperhatikan kondisi anak dan orang tuanya. Pada kegiatan ini, tidak semu anak memiliki pengalaman kegiatan bermalam di luar rumah. Dengan pertimbangan tersebut, desain awal program ini diset dengan durasi singkat;

(2) Jenis Proyek, jenis proyek mempertimbangakan kemampuan anak dalam menyelesaikan target produk. Dalam hal ini, diperhatikan juga bagaimana agar program ini dapat diterima oleh anak dengan berbagai jenjang kelas; (3) Bentuk Kegiatan, bentuk kegiatan diset dengan memperhatikan sebaran kelompok anak, kesesuaian dengan waktu dan bentang alam, serta kebermaknaan kegiatan. Oleh karena itu, penempatan proyek dan penentuan jenis target produk yang tepat sangat diperhatikan dalam pengaturan kegiatan dalam program ISC.

Tabe1 2. Perubahan pada Tahap Design dalam Program Islamic Science Camp

\begin{tabular}{|c|c|c|c|}
\hline Komponen & Tahap I & Tahap II & Tahap III \\
\hline Durasi Waktu & $\begin{array}{l}\text { Set kegiatan camp } \\
\text { didesain } 3 \text { hari } 2 \\
\text { malam }\end{array}$ & $\begin{array}{l}\text { Set kegiatan dipadatkan } \\
\text { menjadi } 2 \text { hari } 1 \text { malam }\end{array}$ & \\
\hline Jenis Proyek & $\begin{array}{l}\text { Terdapat } 9 \text { proyek } \\
\text { yang harus dikerjakan } \\
\text { oleh kelompok anak }\end{array}$ & $\begin{array}{l}\text { Terdapat penggantian jenis } \\
\text { proyek yaitu proyek } \\
\text { pembuatan sabun menjadi } \\
\text { proyek pengharum ruangan }\end{array}$ & $\begin{array}{l}\text { Terdapat penambahan jenis proyek } \\
\text { yang disesuaikan dengan durasi waktu } \\
\text { serta penambahan media } \\
\text { pembelajaran: } \\
\text { 1) Penggunaan media audio visual } \\
\text { dalam Kajian Sains Islami } \\
\text { 2) Proyek pembuatan gantungan } \\
\text { kunci dari resin ditambahkan } \\
\text { sebagai salah satu proyek di akhir } \\
\text { kegiatan }\end{array}$ \\
\hline $\begin{array}{l}\text { Bentuk } \\
\text { kegiatan }\end{array}$ & $\begin{array}{lr}\text { Rangkaian kegiatan } \\
\text { diset berupa daftar } \\
\text { kegiatan dan target } \\
\text { produk }\end{array}$ & $\begin{array}{l}\text { Rangkaian kegiatan diatur } \\
\text { sesuai dengan kesesuian } \\
\text { waktu, semisal: } \\
\text { 1) Proyek pembuatan es krim } \\
\text { dilaksanakan di siang hari } \\
\text { 2) Totebag ecoprint sebagai } \\
\text { souvenir dan ditunjukkan } \\
\text { kepada orang tuanya }\end{array}$ & $\begin{array}{l}\text { Terdapar set } \text { kompetisi antar } \\
\text { kelompok dalam proses pembuatan } \\
\text { produk }\end{array}$ \\
\hline
\end{tabular}

Detail perubahan hasil verifikasi dengan pakar pendidikan IPA dan praktisi anak ditunjukkan pada Tabel 2. Adapun detail model program ISC ditunjukkan pada Gambar 2. yang mana terlihat bahwa ada keterkaitan antar komponen program. Terdapat dua kegiatan dalam ISC yang berkaitan dengan aktivitas berbasis proyek dan habituasi anak. Aktivitas-aktivitas yang berbasis proyek inilah yang berkaitan langsung dengan pembelajaran IPA dan aspek kecintaan pada alam. Adapun nilai-nilai Islam diajarkan secara tidak langsung dalam rangkaian aktivitasnya. Nilai-nilai Islam termuat langsung dalam pembelajaran habituasi anak berupa pengamalan ajaran Islam dalam aktivitas keseharian. 


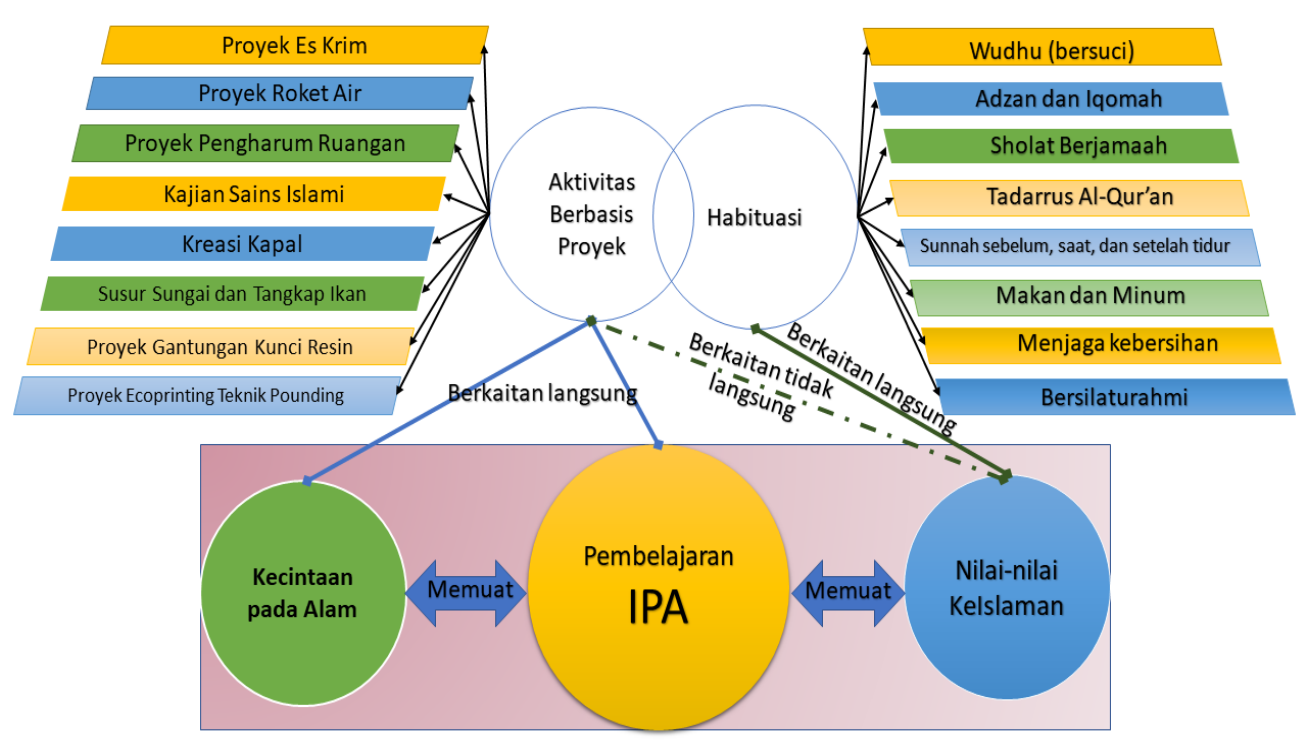

Gambar 2. Desain Model Keterkaitan Antar Komponen pada Program Islamic Science Camp

\section{Tahap Develop}

Pada tahap ini dilaksanakan implementasi program sesuai dengan rancangan awal. Aktivitas yang dikerjakan adalah kegiatan habituasi dan aktivitas berbasis proyek. Kegiatan habituasi anak mencakup pembelajaran dan pembenaran pengamalan ajaran Islam dalam keseharian yang meliputi: (1) aktivitas bersuci; (2) tata cara adzan dan iqomah; (3) pembiasaan sholat berjama'ah; (4) Tadarrus Al-qur'an dan tajwid; (5) Sunnah pada aktivitas tidur; (6) Sunnah dalam makan dan minum; (7) Sunnah dalam menjaga kebersihan; (8) Konsep silaturahmi. Pada pembelajaran habituasi, anak terlihat dapat mengikuti dan mempraktikkan dengan baik. Anak juga dapat mengikuti dengan baik, meskipun kelompok anak terdiri dari anak-anak yang baru saja mengenal dan memiliki perbedaan level kelas formal dan usia. Mereka dapat dengan segera membaur dan beraktivitas dengan baik. Atmosfer pada kegiatan habituasi penuh dengan keakraban meskipun mereka berasal dari berbagai daerah dan instansi. Senada dengan itu, kajian penelitian lain menggarisbawahi bahwa aktivitas di luar ruangan dapat memperkuat persahabatan (Taş, 2019). Beberapa aktivitas pada kegiatan habituasi ditunjukkan pada Gambar 3.

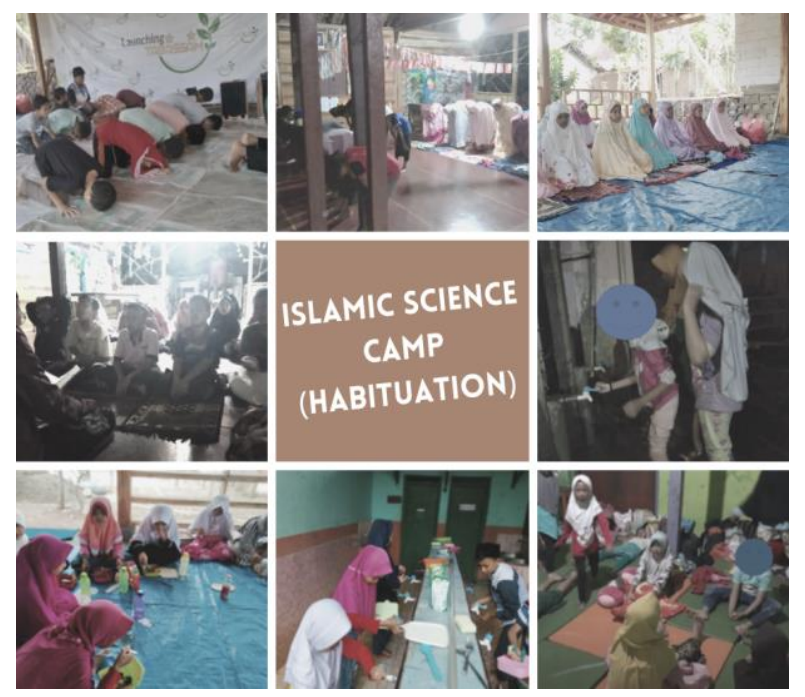

Gambar 3. Pembinaan Habituasi Anak untuk Kemandirian dan Sesuai dengan Keseharian Muslim

Pada aktivitas yang berbasis proyek, anak dikelompokkan secara heterogen. Kecintaan terhadap alam, serta nilai-nilai ke-Islaman diajarkan secara tersirat pada aktivitas yang mereka 
kerjakan. Kelompok anak difasilitasi dalam melakukan proyek dengan target produk tertentu. Dalam pelaksanaanya, fasilitator memberikan kejelasan konsep sains yang ada pada aktivitas yang sedang mereka kerjakan secara singkat. Fokus kegiatan lebih pada aktivitas bands-on sehingga diperoleh target produk yang diharapkan ataupun target pemahaman dan keterampilan. Kegiatan praktik pembuatan proyek mengarah pada ragam aktivitas yang dikerjakan di luar ruangan. Pembelajaran di luar ruangan dimungkinkan untuk dilaksanakan secara konstruktif (Glaab \& Heyne, 2019). Pembelajaran outdoor lebih menantang siswa untuk mengaitkan materi teori dalam buku dan kenyataan di lapangan sehingga konsep dapat diolah dengan baik (Arianti \& Aminatun, 2019). Lingkungan luar ruangan juga merupakan sumber belajar yang dapat menghidupkan suasana dan mengurangi ketergantungan yang berlebihan pada buku dan suasana kelas tradisional (Özgen, 2011; Tatar \& Bağriyanik, 2012). Detail keterkaitan masing-masing komponen program ISC dengan aktivitas berbasis proyek ditunjukkan pada Tabel 3.

Tabel 3. Keterkaitan Antara Kegiatan ISC, Konsep Sains, Kecintaan Terhadap Alam, Serta NilaiNilai Keislaman

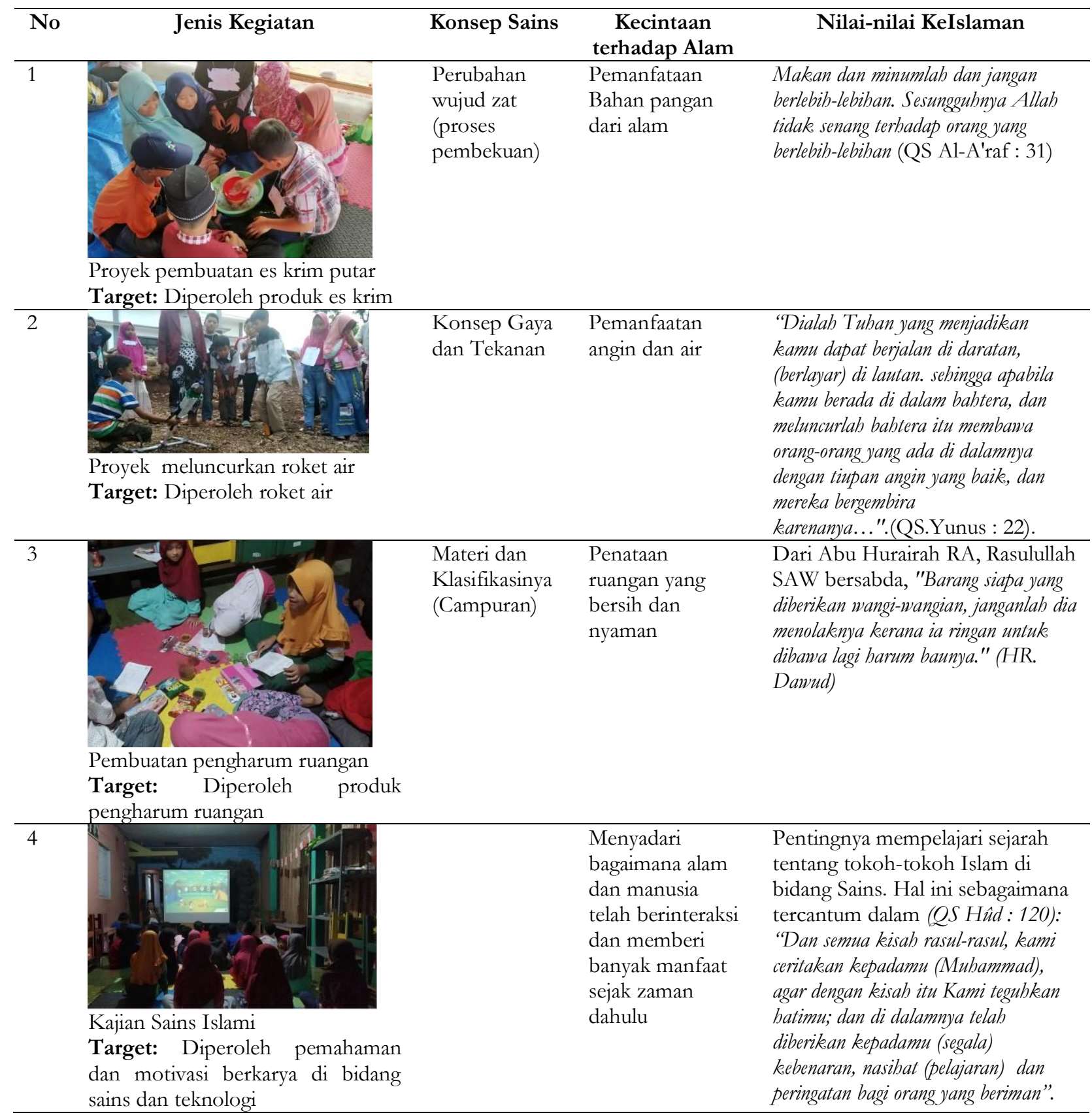




\begin{tabular}{|c|c|c|c|c|}
\hline No & Jenis Kegiatan & Konsep Sains & $\begin{array}{c}\text { Kecintaan } \\
\text { terhadap Alam }\end{array}$ & Nilai-nilai KeIslaman \\
\hline 5 & $\begin{array}{l}\text { Proyek pembuatan kapal dan } \\
\text { meluncurkannya } \\
\text { Target: Diperoleh kreasi kapal } \\
\text { yang dapat diluncurkan pada arus } \\
\text { sungai }\end{array}$ & $\begin{array}{l}\text { Konsep } \\
\text { Tekanan } \\
\text { Konsep } \\
\text { Energi }\end{array}$ & $\begin{array}{l}\text { Memperlihatkan } \\
\text { bagaimana alam } \\
\text { (sungai) dapat } \\
\text { memberikan } \\
\text { manfaat untuk } \\
\text { aktivitas rekreasi } \\
\text { dan transportasi }\end{array}$ & $\begin{array}{l}\text { "Dialah Tuhan yang menjadikan } \\
\text { kamu dapat berjalan di daratan, } \\
\text { (berlayar) di lautan. sebingga apabila } \\
\text { kamu berada di dalam babtera, dan } \\
\text { meluncurlab babtera itu membawa } \\
\text { orang-orang yang ada di dalamnya } \\
\text { dengan tiupan angin yang baik, dan } \\
\text { mereka bergembira } \\
\text { karenanya...".(QS.Yunus : 22). }\end{array}$ \\
\hline 6 & $\begin{array}{l}\text { Susur sungai dan Tangkap Ikan } \\
\text { Target: Diperoleh pengetahuan } \\
\text { tentang ekosistem perairan }\end{array}$ & $\begin{array}{l}\text { Ekosistem } \\
\text { perairan }\end{array}$ & $\begin{array}{l}\text { Memperlihatkan } \\
\text { bagimana } \\
\text { interaksi } \\
\text { komponen } \\
\text { abiotik dan } \\
\text { biotik yang ada } \\
\text { di ekosistem } \\
\text { perairan }\end{array}$ & $\begin{array}{l}\text { Ia memancarkan daripadanya mata } \\
\text { airnya, dan (menumbubkan) tumbub- } \\
\text { tumbubannya. (QS An-Nazi'at:31) }\end{array}$ \\
\hline 7 & $\begin{array}{l}\text { Pembuatan Gantungan Kunci dari } \\
\text { Resin } \\
\text { Target: Diperoleh produk } \\
\text { gantungan kunci }\end{array}$ & $\begin{array}{l}\text { Materi dan } \\
\text { Klasifikasinya } \\
\text { (Campuran) }\end{array}$ & $\begin{array}{l}\text { Menunjukkan } \\
\text { pemanfaatan } \\
\text { bahan alam }\end{array}$ & $\begin{array}{l}\text { QS al-Mulk: } 15 \text { yang artinya. } \\
\text { "Dialah yang menjadikan bumi untuk } \\
\text { kamu yang mudah dijelajabi, maka } \\
\text { jelajabilah di segala penjurunya dan } \\
\text { makanlah sebagian dari rejeki-Nya. } \\
\text { Dan banya kepada-Nya lah kami } \\
\text { dibangkitkan." }\end{array}$ \\
\hline 8 & $\begin{array}{l}\text { Pembuatan Ecoprinting dengan } \\
\text { Teknik Pounding } \\
\text { Target: Diperoleh produk totebag } \\
\text { ecoprint }\end{array}$ & $\begin{array}{l}\text { Morfologi } \\
\text { Tumbuhan }\end{array}$ & $\begin{array}{l}\text { Menunjukkan } \\
\text { pemanfaatan } \\
\text { bahan alam }\end{array}$ & $\begin{array}{l}\text { QS al-Mulk: } 15 \text { yang artinya. } \\
\text { "Dialah yang menjadikan bumi untuke } \\
\text { kamu yang mudab dijelajabi, maka } \\
\text { jelajabilah di segala penjurunya dan } \\
\text { makanlah sebagian dari rejeki-Nya. } \\
\text { Dan hanya kepada-Nya lab kami } \\
\text { dibangkitkan." }\end{array}$ \\
\hline
\end{tabular}

Penjaringan data melalui lembar kesan pada lima aktivitas berbasis proyek menunjukkan ragam pola yang berbeda. Masing-masing anak memiliki kesan yang berbeda pada masing-masing kegiatan. Setiap anak mengembangkan makna unik dalam pengalaman mereka (Behrendt \& Franklin, 2014). Hal ini sebagaimana ditunjukkan pada pola kesan pada Gambar 4. Kesan yang muncul pada aktivitas menunjukkan bahwa anak memaknai apa yang sedang dikerjakannya. Pada aktivitas membuat es krim, kesan yang paling banyak muncul ada pada aktivitas memutar. Kelompok anak memaknai aktivitas memutar sebagai aktivitas yang seru dan menyenangkan untuk memperoleh target produk es krim. Adapun pada aktivitas membuat roket, anak memberikan kesan terbanyak pada proses meluncurkan roket air. Mereka menikmati proses kompetisi dan mengamati proses peluncuran roket air. Pada aktivitas membuat pengharum ruangan, kesan anak ada pada jenis varian aroma yang dibuat. Anak juga memiliki kesan baik pada proses berkreasi 
pada saat membuat kapal. Kegiatan luar ruangan (termasuk aktivitas susur sungai) merupakan pengajaran sains yang secara induktif menekankan pendekatan berpusat pada interaksi terhadap lingkungan (Arianti \& Aminatun, 2019). Selain itu, anak juga menunjukkan antusiasme kesan yang sangat baik pada pengenalan tokoh-tokoh sains.

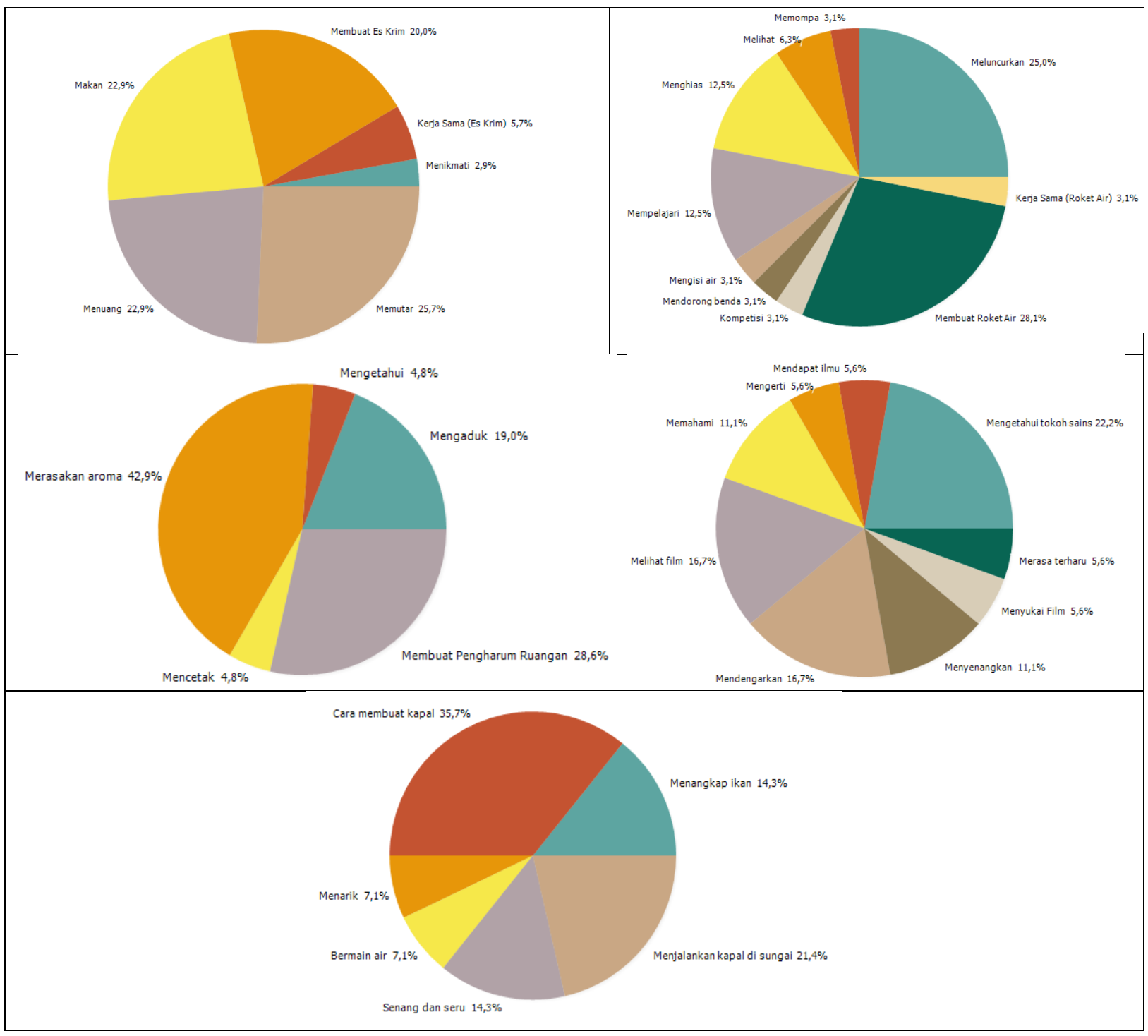

Gambar 4. Pola Kesan pada Beberapa Aktivitas yang Disajikan pada Islamic Science Camp

Analisis secara keseluruhan pada kesan anak ditunjukkan pada word cloud dan bar chart sebagaimana pada Gambar 5. Kesan positif didominasi pada aktivitas "memutar", "merasakan aroma", dan "meluncurkan roket air". Dengan demikian, tiga proyek utama yang akan terus dipertahankan pada penyusunan program lanjutan adalah aktivitas pembuatan es krim, pembuatan pengharum ruangan, serta peluncuran roket air. 


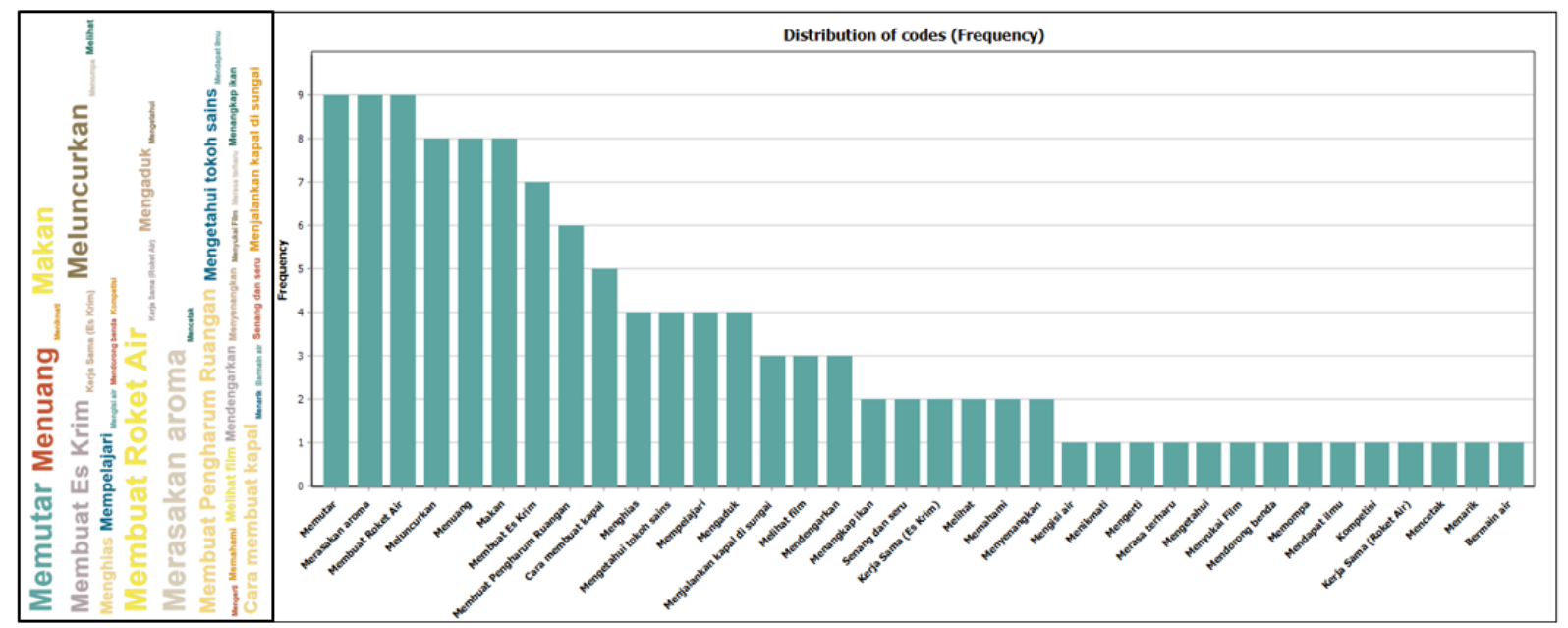

Gambar 5. Distribusi kesan pada aktivitas Islamic Science Camp

Selain kesan yang dijaring secara langung kepada anak, ragam kesan positif juga ditunjukkan oleh orang tua anak. Ragam kesan ditunjukkan pada Gambar 6. Kesan yang ditunjukkan oleh orang tua dapat dikelompokkan pada: (1) Aspek keterlaksanaan program, orang tua memberikan respon untuk memberikan up date dokumentasi kegiatan anak dan memberikan respon positif terhadap setiap tahapan kegiatan; (2) Aspek kondisi aksi anak dalam aktivitas program, orang tua memberikan pernyataan positif bagaimana aksi anak pada setiap tahapan program; (3) Aspek keberlanjutan program, orang tua memberikan pernyataan positif berkaitan dengan perubahan sikap anak, serta keberlanjutan aktivitas proyek yang mereka repetisi dan kembangkan setelah kegiatan.

\begin{tabular}{|c|c|}
\hline 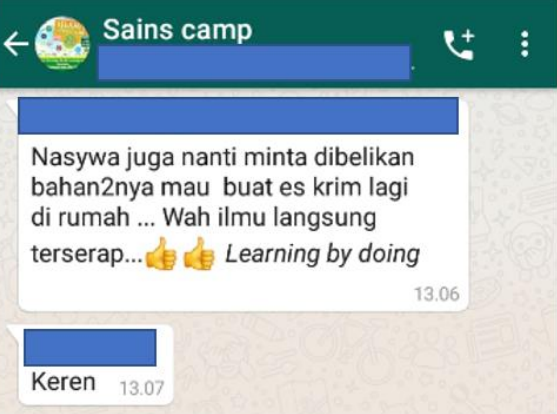 & $\begin{array}{l}\text { Sains camp } \\
\text { Masya Allah, sesampainya di rumah } \\
\text { Nasywa menceritakan keseruan di } \\
\text { Alfa Kids, termasuk kebaikan dari } \\
\text { kakak pendamping yang selalu } \\
\text { mengawal peserta dg penuh kasih } \\
\text { sayang @i... Sebelum tidur pun sholat } \\
\text { isya' berjamaah dulu... Banyak sekali } \\
\text { perubahan Positif setelah pulang } \\
\text { dari pondok walaupun kilat namun } \\
\text { memikat... }\end{array}$ \\
\hline $\begin{array}{l}\text { Sains camp } \\
\text { Kak Ali... } \\
\text { Mohon dishare cara dan bahan } \\
\text { science kmrn ya... } \\
\text { Mau dicoba dirumah... }\end{array}$ & 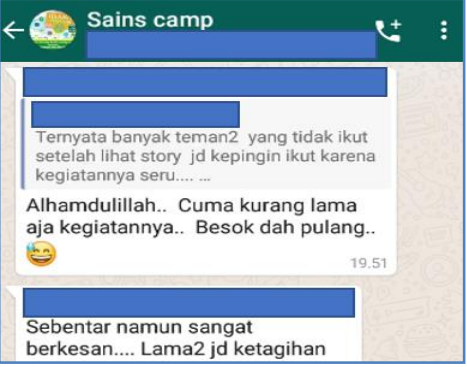 \\
\hline
\end{tabular}

Gambar 6. Respon yang Diberikan oleh Para Orangtua/Wali Peserta ISC

Didasarkan pada kesan anak dan orang tua, dilakukan refleksi dan evaluasi program ISC yang terlaksana. Adapun hasil refleksi dan evaluasi mencakup: (1) Kelebihan Program, pada aspek keterlaksanaan, anak begitu bersemangat dan menikmati kegiatan yang diselenggarakan pada ISC. Baik orang tua dan anak menghendaki penambahan durasi program dengan pendalaman pada proyek serta penambahan aktivitas proyek. Kegiatan belajar di luar ruangan direkomendasikan 
dalam pembelajaran sains, terutama saat belajar tentang lingkungan dan alam (Taş, 2019). Pembelajaran yang dirancang dengan set alam dapat memotivasi siswa (anak) untuk mengapresiasi dan memahami konsep yang diajarkan di kelas (Ramachandiran \& Dhanapal, 2016); (2) Kekurangan Program, belum adanya panduan pelaksanaan aktivitas ISC yang bermuatan ragam aktivitas proyek dan pengamalan ajaran Islam dalam habituasi. ISC yang dilaksanakan tidak menggunakan panduan dengan format khusus. Selain itu, target yang diharapkan pada masingmasing aktivitas belum diukur secara kuantitatif.

Hasil refleksi ini kemudian dijadikan rujukan untuk penyusunan desain awal panduan pelaksanaan program ISC (Gambar 7). Kajian riset sebelumnya menekankan pada proses mengintegrasikan pembelajaran di kelas dengan kegiatan di luar ruang dapat dilakukan lebih jauh untuk dapat memberikan makna pada pembelajaran IPA, yang tidak dibatasi oleh ruang kelas atau laboratorium (Rahmawati et al., 2020). Dengan demikian, perlu disusun panduan skoring untuk menilai target produk pada masing-masing aktivitas berbasis proyek. Desain ini akan diuji coba lebih lanjut pada aktivitas ISC dengan menggunakan siklus kedua model R\&D.

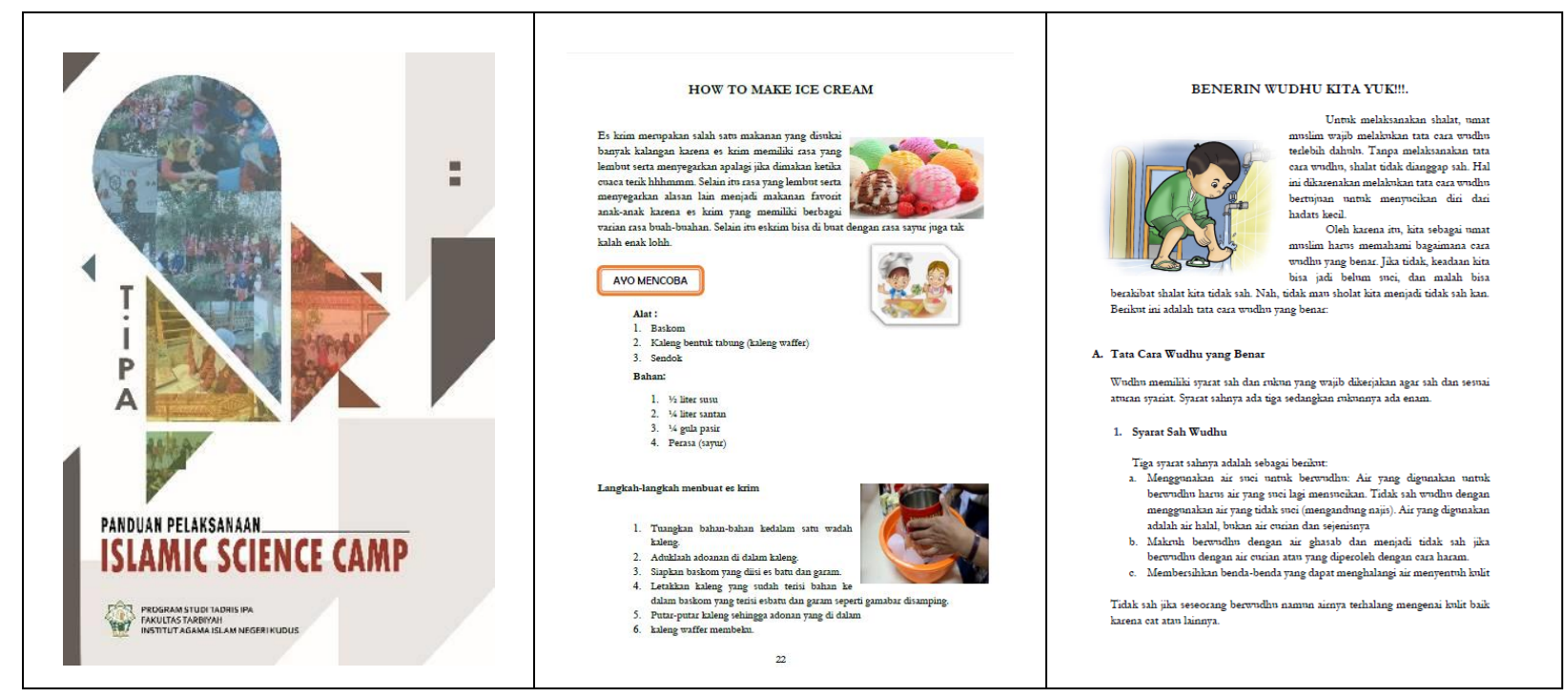

Gambar 7. Hasil Tindak Lanjut Refleksi Program ISC Berupa Panduan Pelaksanaan Kegiatan

Islamic Science Camp merupakan kegiatan pembelajaran IPA yang diselenggarakan melalui aktivitas camp (perkemahan) yang memuat kegiatan habituasi dengan menekankan pengamalan nilai-nilai ke-Islaman, serta aktivitas pembelajaran IPA berorientasi pada proyek, bands-on activity yang menumbuhkan kecintaan pada alam. Topik IPA yang diujicobakan berkaitan dengan (1) perubahan wujud zat, (2) konsep gaya dan tekanan, (3) materi dan klasifikasinya, (4) konsep energi, (5) ekosistem perairan, dan (6) morfologi tumbuhan. Nilai-nilai Islam ditekankan pada pengarahan kegiatan habituasi anak, serta pemberian motivasi anak melaui tokoh-tokoh Islam bidang sains dan teknologi. Proyek sains yang dilaksanakan pada program ISC mencakup (1) proyek pembuatan es krim putar; (2) proyek meluncurkan roket air, (3) pembuatan pengharum ruangan, (4) kajian sains islami, (5) proyek pembuatan kapal dan meluncurkannya, (6) susur sungai dan tangkap ikan, (7) pembuatan gantungan kunci dari resin, dan (8) pembuatan ecoprinting dengan teknik pounding. Beragam kesan positif diperoleh dari anak dan orang tua yang terlibat. Kesan positif anak didominasi pada aktivitas "memutar", "merasakan aroma", dan "meluncurkan roket air". Pada aspek keberlanjutan ditunjukkan adanya repetisi dan eksperimen lanjutan oleh anak di luar program ISC. Hasil refleksi pelaksanan program mengarah pada perlunya penyusunan desain awal panduan pelaksanaan program ISC, serta panduan skoring untuk menilai target produk pada masing-masing aktivitas berbasis proyek. 


\section{PENGHARGAAN}

Kami mengucapkan terima kasih kepada Madrasah Alfa Kids yang berlokasi di Kecamatan Cluwak, Kabupaten Pati atas dukungan berupa sarana dan prasarana dalam pelaksanaan program Islamic Science Camp. Selain itu, kami mengucapkan terima kasih kepada para anak dan orang tua yang telah bersedia sebagai subyek uji coba, berpartisipasi aktif, dan memberikan dukungan positif pada pelaksanaan desain awal program ISC.

\section{REFERENSI}

Adu, P. (2019). Using QDA Miner Lite to analyze qualitative data. In P. Adu (Ed.), A Step-by-Step Guide to Qualitative Data Coding. Routledge. Retrieved from https://doi.org/10.4324/9781351044516-10

Amril, A. (2018). Nilainisasi Pembelajaran Sains (Upaya Pembelajaran Integrasi-Interkoneksi Agama Dan Sains). Journal of Natural Science and Integration, 1(2), 133-144.

Anita, A. (2013). Penerapan Pendekatan Konstruktivisme Untuk. Meningkatkan Hasil Belajar Siswa Pada Pembelajaran IPA Materi Gaya (Penelitian Tindakan Kelas Di Kelas V Sd Negeri Bukanagara Lembang Semester II Tahun Ajaran 2012/ 2013). repository.upi.edu. Universitas Pendidikan Indonesia.

Arianti, Y., \& Aminatun, T. (2019). An analysis of outdoor learning towards students' outcomes in learning biology. Journal of Physics: Conference Series, 1241(1). Retrieved from https://doi.org/10.1088/1742-6596/1241/1/012061

Ash, D., \& Wells, G. (2006). Dialogic Inquiry in Classroom and Museum. In N. C. Z. Bekerman, B. Burbles, \& D. Silberman-Keller (Eds.), The Informal Education Reader (pp. 35-54). New York: Peter Lang.

Asoko, H. (2000). Learning to teach science in the primary school. In R. Millar, J. Leach, \& J. Osborne (Eds.), Improving Science Education: The contribution of research (1st ed., pp. 79-92). Buckingham, Philadelphia, USA: Open University Press.

Badan Penelitian dan Pengembangan, K. P. dan K. (2013). Kompetensi Dasar Sekolah Menengah Pertama (SMP)/ Madrasah Tsanawiyah (MTs). Jakarta: Kementrian Pendidikan dan Kebudayaan.

Bamberger, Y., \& Tal, T. (2008). Multiple outcomes of class visits to natural history museums: The students' view. Journal of Science Education and Technology, 17(3), 274-284. Retrieved from https://doi.org/10.1007/s10956-008-9097-3

Barlia, L. (2008). Sains untuk anak: Hakikat pembelajaran sains untuk sekolah dasar. Cakrawala Pendidikan, XXVII(2), 11.

Behrendt, M., \& Franklin, T. (2014). A Review of Research on School Field Trips and Their Value in Education, 3, 235-245. Retrieved from https://doi.org/10.12973/ijese.2014.213a 
Cakiroglu, J. (2007). Effects of Hands- on Activity Enriched Instruction on Students ' Achievement and Attitudes Towards, (April), 87-98.

Cassim, F. (2013). Hands On , Hearts On , Minds On : Design Thinking within an Education Context, 2, 190-202.

Chiappetta, E. L., \& Koballa, T. R. (2010). Science Instruction in the Middle and Secondary Schools: Developing Fundamental Knowledge and Skills (7th ed.). United State of America: Pearson Education Inc.

Dillon, J., Rickinson, M., Teamey, K., Morris, M., Choi, M. Y., Sanders, D., \& Benefield, P. (2016). The value of outdoor learning: Evidence from research in the UK and elsewhere. Towards a Convergence Between Science and Environmental Education: The Selected Works of Justin Dillon, (January), 179-185. Retrieved from https://doi.org/10.4324/9781315730486

Glaab, S., \& Heyne, T. (2019). Focus wildlife park: Outdoor learning at workstations for primary school children. Applied Environmental Education and Communication, 1-14. Retrieved from https://doi.org/10.1080/1533015X.2018.1554461

Golshani, M. (1998). The Holy Qur'an and The Science of Nature. New York: Global Publications.

Golshani, M. (2004). Issues in Islam and Science. Tehran: Institute for Humanities and Cultural Studies.

Hofstein, A., \& Rosenfeld, S. (1996). Bridging the gap between formal and informal science learning. Studies in Science Education, 28(1), 87-112. Retrieved from https://doi.org/10.1080/0305726960856008

Imaduddin, M. (2017). Mendesain Ulang Pembelajaran Sains Anak Usia Dini yang Konstriktif melalui STEAM Project-Based Learning yang Bernuansa Islami. In Proceeding AnCoMS 2017: 1st Annual Conference for Muslim Scholars (pp. 950-958). Surabaya: Kopertais Wilayah IV Surabaya.

Imaduddin, M. (2019). Infusing Islamic Values and Sustainable Development Into Chemistry for Pre-Service Islamic Elementary School Teachers. Jurnal Pendidikan Sains (Jps), 7(1), 47. Retrieved from https://doi.org/10.26714/jps.7.1.2019.47-54

Imaduddin, M. (2020). A New Way to Promote Islamization of Science: I-SETS Design for PreService Science Teachers. Journal of Natural Science and Integration, 3(1), 1. Retrieved from https://doi.org/10.24014/jnsi.v3i1.8774

Imaduddin, M., \& Khafidin, Z. (2018). Ayo Belajar IPA dari Ulama: Pembelajaran Berbasis SosiScientific Issues di Abad ke-21. Thabiea: Journal of Natural Science Teaching, 01(02), 102-120.

Imaduddin, M., \& Zuhaida, A. (2019). STREAMIN Model for the Next Generation of Science Education in Indonesia. In Journal of Physics: Conference Series (Vol. 1233). Retrieved from https://doi.org/10.1088/1742-6596/1233/1/012096 
Inan, H. Z., \& Inan, T. (2015). 3Hs Education: Examining hands-on, heads-on and hearts-on early childhood science education. International Journal of Science Education, (July 2015). Retrieved from https://doi.org/10.1080/09500693.2015.1060369

Karpudewan, M., Ismail, Z., \& Mohamed, N. (2013). Pre-service teachers' understanding and awareness of sustainable development concepts. Asia Pacific Journal of Educators and Education, $28,117-130$.

Martin, S. (2006). Where practice and theory intersect in the chemistry classroom: Using cogenerative dialogue to identify the critical point in science education. Cultural Studies of Science Education, 1(4), 693-720. Retrieved from https://doi.org/10.1007/s11422-006-9031-z

National Science Teachers Association. (2003). Standards for science teacher preparation.

Özgen, N. (2011). A different approach to physical geography teaching method: Trip-observation supported education. Marmara Journal of Geography, 23, 373-388.

Rahmawati, R. F., Imaduddin, M., Haqiqi, A. K., Fikri, A. A., Fawaida, U., Prasetyo, D. R., \& Faikhamta, C. (2020). Assessing Psychosocial Outdoor Learning Environment of Preservice Science Teachers through The Field Trip Experiences. Participatory Educational Research, 7(2), 135-150. Retrieved 31 May 2020 from https://doi.org/10.17275/per.20.24.7.2

Ramachandiran, M., \& Dhanapal, S. (2016). Evaluation of the Effectiveness of Field Trips in the Teaching and Learning of Biosciences. In S. F. Tang \& L. Logonnathan (Eds.), Assessment for Learning Within and Beyond the Classroom. Springer Science+Business Media Singapore. Retrieved from https://doi.org/10.1007/978-981-10-0908-2

Rickinson, M., Dillon, J., Teamey, K., Morris, M., Choi, M. Y., Sanders, D., \& Benefield, P. (2004). A review of research on outdoor learning.

Taş, E. (2019). Analysis of the influence of outdoor education activities on seventh grade students. Participatory Educational Research (PER), 6(2), 122-143.

Tatar, N., \& Bağriyanik, K. E. (2012). Opinions of Science and Technology Teachers about Outdoor Education Fen v e Teknoloji Dersi Öğretmenlerinin Okul D1Ģ1 Eğitime Yönelik GörüG,leri. Elementary Education Online, 11(4), 883-896.

Thamrin, H. (2017). Rekontruksi Ecoreligius Orang Melayu Solusi Penyelamatan Lingkungan. AlFikera: Jurnal Ilmiab Keislaman, 16(1), 99-136.

The OECD Programme for International Student Assessment. (2019). PIS A 2018 Results (Volume I). Retrieved from Paris:

Thiagarajan, S., Semmel, D. S., \& Semmel, M. I. (1974). Instructional Development for Training Teachers of Exceptional Children. Minnesota: Leadership Training Institute/ Special Education, University of Minnesota. 
Wardani, W., \& Mulyani, M. (2013). Eko-Teologi Al-Qur`an: Sebuah Kajian Tafsir Al-Qur`an Dengan Pendekatan Tematik. Ilmu Ushuluddin, 12(2), 167-193. Retrieved from https://doi.org/10.18592/jiu.v12i2.532

Wisudawati, A. W., \& Sulistyowati, E. (2014). Metodologi Pembelajaran IPA. Yogyakarta: Bumi Aksara.

Zidny, R., \& Eilks, I. (2018). Indigenous knowledge as a socio-cultural context of science to promote transformative education for sustainable development: insights into a case study on the baduy community (indonesia). Building Bridges across Disciplines for Transformative Education and a Sustainable Future, (October), 249-256.

Zion, M., \& Mendelovici, R. (2012). Moving from structured to open inquiry: Challenges and limits. Science Education International, 23(4), 383-399. 